\title{
Función y deformación del recurso de unificación de jurisprudencia
}

\author{
Rodrigo Correa González*
}

\begin{abstract}
RESUMEN
El recurso de unificación de jurisprudencia en materia laboral tiene por objeto contribuir a satisfacer el interés público en una jurisprudencia uniforme. La sentencia de unificación que dicta la Corte Suprema elimina la dispersión jurisprudencial que justifica la interposición del recurso. Eso no significa que tengan efecto vinculante, sino solo que no es posible recurrir de unificación cuando una materia ya ha sido unificada. La Corte Suprema ni siquiera le reconoce este efecto. Para que el recurso recupere su funcionalidad, es necesario dictar una ley interpretativa.
\end{abstract}

$$
\text { Jurisprudencia - precedentes - Corte Suprema }
$$

\section{The deformation of the writ for the unification of case law}

\begin{abstract}
The writ for the unification of case law in labor cases aims at satisfying the public interest in the regularity of case law. Its resolution by the Supreme Court removes the dispersion that justifies the filing of the writ. This does not mean that it has precedential force (stare decisis), but that it bars raising the same issue once again to the Court. The Court does not even recognize this limited effect of its own decisions. A statutory solution is needed in order to restore the functionality of the writ.
\end{abstract}

Case law - precedents - Supreme Court

* Licenciado en Ciencias Jurídicas y Sociales, Universidad de Chile. Doctor en Derecho, Universidad de Yale, Estados Unidos. Profesor de Derecho, Universidad Adolfo Ibáñez, Chile. Correo electrónico: rodrigo.correa@uai.cl

Artículo recibido el 10.9.2019 y aceptado para su publicación el 9.4.2020. 

somete a conocimiento de la Corte Suprema (en adelante, indistintamente "la Corte" o "la Suprema") una materia de derecho que ha sido objeto de distintas interpretaciones sostenidas en fallos de los tribunales superiores de justicia. El recurso tiene por objeto la unificación de la jurisprudencia ${ }^{1}$.

Las características y alcances del recurso de unificación no se encuentran completamente determinados por el texto de la ley ${ }^{2}$. En la doctrina y la práctica se plantea la pregunta acerca del efecto de la sentencia de unificación. La primera se ha preguntado si tiene algún tipo de efecto vinculante ${ }^{3}$. La Corte, por su parte, al conocer de la admisibilidad de recursos de unificación, ha debido examinar si sus propias sentencias de unificación hacen desaparecer la dispersión jurisprudencial que antes existió. Originalmente la Corte no les reconoció tal efecto. A mediados de 2015 modificó su práctica y comenzó a reconocerlo, declarando inadmisibles los recursos fundados en dispersiones que habían sido removidas por sentencias de unificación. Esta práctica duró dos años, pues a mediados de 2017 la Corte volvió a desconocer el efecto unificador de sus sentencias. De esta oscilación doy cuenta en la primera parte del trabajo.

En la segunda parte presentaré la tesis central: que la sentencia de unificación no es vinculante para causas distintas de aquella en que se pronuncia, pero que elimina la dispersión jurisprudencial hasta entonces existente. El efecto práctico de este efecto es que por no configurarse la causal que justifica su interposición, resultan inadmisibles los recursos contra sentencias consistentes con la última unificación de la Corte y que no se funden en una sentencia posterior a esta unificación que sostenga una doctrina contraria a ella.

Contra esta tesis puede argumentarse que ella perjudica el derecho del litigante vencido a que la Corte Suprema revise lo resuelto. Esta tesis podría buscar asidero en cierta doctrina y jurisprudencia que afirma la existencia de un derecho constitucional al recurso. La tercera parte del trabajo refuta esta posibilidad.

Finalmente, en la conclusión se presentan algunas consideraciones de lege ferenda con el propósito de devolver al recurso efectos consistentes con la función que está llamado a servir.

${ }^{1}$ Delgado Castro, 2011, p. 484; Díaz García, 2015a.

${ }^{2}$ El presente trabajo no tiene por objeto ofrecer un panorama del recurso de unificación de jurisprudencia, que se puede encontrar en Humeres Noguer y Halpern Montecino, 2015. Además, puede consultarse Delgado Castro, 2011; Delgado Castro, 2015; Halpern Montecino y Humeres Noguer, 2010; Halpern Montecino, 2013, Halim Muñoz, 2010; Román Díaz, 2008 y Saldías Cárcamo, 2013.

3 Díaz García, 2015 a. 


\section{LA PRÁCTICA DE LA CORTE}

Durante dos años, entre el 25 de agosto de 2015 y septiembre del 2017, la Corte entendió que no hay "distintas interpretaciones sostenidas en uno o más fallos firmes emanados de Tribunales Superiores de Justicia" cuando la sentencia recurrida se conforma con la doctrina anteriormente unificada por la Corte y las sentencias que el recurso invoca como contradictorias son anteriores a la citada unificación ${ }^{4}$. En consecuencia, los recursos contra sentencias consistentes con la última unificación de la Corte, en la medida en que para configurar las "distintas interpretaciones" invocaban sentencias anteriores a dicha unificación, eran desestimados o declarados derechamente inadmisibles. Desde septiembre del 2017, la Corte ha vuelto a traer en relación los recursos que se fundan en una dispersión jurisprudencial que ya ha sido conocida y unificada, aun cuando no se invoque siquiera una sentencia de corte pronunciada después de la unificación y que la contradiga ${ }^{5}$.

La causa Ávila con Municipalidad de Puerto Montt grafica lo anterior. En ella se sometía a unificación la siguiente materia: si la bonificación proporcional que establece el artículo primero de la Ley $\mathrm{N}^{\circ} 19.933$ alcanza a los docentes del sector municipal. El 20 de noviembre de 2017 la Corte había unificado en el sentido de que no los alcanzaba, doctrina que reiteró el 14 de diciembre del mismo año ${ }^{6}$. Veintiún días después, el 4 de enero de 2018, se dio cuenta en sala de la admisibilidad del recurso en Ávila con Municipalidad de Puerto Montt. Este impugnaba lo resuelto por la Corte de Apelaciones de Puerto Montt el 21 de septiembre de 2017, que estaba en consonancia con la jurisprudencia unificada. Para justificar la existencia de dispersión jurisprudencial, el recurso

${ }^{4}$ El 25 de agosto la Corte pronunció sentencias en tres causas de tabla rechazando sendos recursos de unificación, con un argumento puramente formal: la materia sometida a unificación ya se encontraba unificada por sentencia de la Corte (Corte Suprema, 25.8.2015, roles 29727-2014, 30196-2014 y 30197-2014). A partir de esa fecha, la Corte declaró inadmisible los recursos que sometían a su conocimiento materias ya unificadas que no habían sido objeto de posteriores sentencias de cortes que se apartaran de la jurisprudencia unificada. A modo ejemplar, vid. declaraciones de inadmisibilidad de 21.6.2017 (rol 27910-2017), 25.7.2017 (rol 31969-2017), 3.8.2017 (rol 14633-2017), 8.8.2017 (rol 34.524-2017), 16.08.2017 (roles 34234-2017 y 34681-14), 21.8.2017 (rol 35195-2017) y 29.8.2017 (rol 30194-2017).

${ }^{5}$ Los recursos de unificación en causas roles 25.003-2017 y 34.626-2017 aparecen con notas de acuerdo el 29 de junio y 7 de agosto de 2017, respectivamente. Aunque no es posible afirmarlo categóricamente, es probable que el acuerdo haya consistido en declarar su inadmisibilidad por encontrarse unificada la materia. En efecto, el examen de admisibilidad puede dar lugar a una decisión de inadmisibilidad o a una decisión de traer los autos en relación. Esta última decisión se adopta en sala, sin previa nota de acuerdo. La nota de acuerdo indica que la decisión es de inadmisibilidad, al menos parcial. Por otra parte, ambos recursos recurrían contra sentencias consistentes con la doctrina unificada por la Corte, sin invocar una dispersión subsecuente. Por ello, bajo la doctrina imperante desde el 25 de agosto de 2015, cabía estimar ambos recursos inadmisibles por encontrarse unificada la materia que sometían a unificación. No obstante, por resoluciones de 23 de noviembre y 12 de septiembre de 2017 se ordenó traer ambos recursos en relación. En consecuencia, es posible situar a mediados de septiembre de 2017 el giro en la jurisprudencia de admisibilidad de la Corte.

${ }^{6}$ Corte Suprema, 20.11.2017, rol 8090-2017 y 14.12.2017, rol 10422-2017. La primera de las citadas sentencias importó un giro en la jurisprudencia. Véanse también Corte Suprema, 29.12.2015, roles 50242015, 5511-2015, 3270-2015 y 4924-2015. 
invocó diversos fallos, el último de los estos había sido pronunciado por la misma Corte de Apelaciones de Puerto Montt el 14 de junio de 2017. Conforme con la práctica de la Corte entre agosto de 2015 y septiembre de 2017, este recurso habría sido declarado inadmisible, pues la materia había sido unificada por última vez el 14 de diciembre de 2017, y no se había acreditado que con posterioridad a esa fecha se hubiera vuelto a dispersar ${ }^{7}$. La Corte, sin embargo, trajo los autos en relación. La causa se vio y se acordó el 24 de mayo, casi cinco meses después de haberse ordenado traerla en relación. Y fue fallada el 16 de agosto, más de siete meses después de dicha orden ${ }^{8}$. El recurso fue desestimado. Estos siete meses de dilación, los costos en honorarios para las partes, los dieciocho minutos de alegatos de las partes ${ }^{9}$, más el tiempo para la relación de la causa y redacción de la sentencia, se habrían evitado con la declaración en cuenta de la inadmisibilidad del recurso, que defenderé como correcta en la siguiente sección.

La actual práctica de la Corte del recurso significa lo siguiente: cualquier sentencia que una Corte pronuncie en una materia que ha sido alguna vez objeto de unificación, sea cual sea la interpretación que sostenga, puede ser impugnada por el recurso. Así, cualquier sentencia de Corte que resuelva la cuestión del alcance del bono proporcional de la Ley $\mathrm{N}^{\circ} 19.933$, puede ser impugnada mediante el recurso de unificación. Y lo mismo vale para toda otra materia que alguna vez haya sido conocida por la Corte en unificación de jurisprudencia. La razón es sencilla: si la Corte unificó la materia, es porque había dispersión. Y si la unificación no la hace desaparecer, esa vieja dispersión servirá de fundamento para impugnar cualquier sentencia que se dicte en el futuro respecto de la misma materia. El resultado es del todo irracional y reñido con la finalidad del recurso. De ser un recurso diseñado para que la Corte Suprema intervenga solo cuando hay dispersión jurisprudencial en un punto de derecho relevante en juicios laborales, pasa a ser un recurso con una selectividad arbitraria.

Las razones que llevaron a la Corte a modificar en septiembre de 2017 su práctica son desconocidas. Simplemente comenzó a traer en relación causas que antes habría declarado inadmisibles. Junto con ello, dejó de declarar recursos inadmisibles en razón de encontrase actualmente unificada la materia de derecho sometida a unificación ${ }^{10}$.

${ }^{7}$ La Corte también había unificado la materia con posterioridad a la cuenta del recurso el 4 de enero de 2018 y dos días antes de la vista de la causa (Corte Suprema, 22.5.2018, rol 37867-2017). En esta situación (unificación posterior al decreto de autos en relación, pero anterior a la vista de la causa) parece recomendable que, terminada la relación del asunto, el presidente de la sala haga ver a los abogados que la materia ha sido recientemente unificada en un sentido coincidente con la sentencia que viene impugnada, invitando a los abogados a alegar en torno a la pregunta de si todavía existe una dispersión jurisprudencial que demande unificación por la Corte. Y salvo que se demuestre que la dispersión permanece, sea porque con posterioridad a la unificación se ha vuelto a dictar sentencia inconsistente con la doctrina unificada, o porque la materia del recurso no es exactamente la misma que fue unificada, la Corte debiera rechazar el recurso en razón de no haber interpretaciones distintas sostenidas por los tribunales superiores de justicia.

${ }^{8}$ Corte Suprema, 16.8.2018, rol 42009-2017.

${ }^{9}$ Según consta de la certificación estampada por la señora relatora.

${ }^{10}$ La última resolución declarando inadmisible un recurso de unificación por haber dejado de existir dispersión jurisprudencial fue pronunciada el 29 de agosto (acuerdo de 5 de julio) de 2017 en causa rol 30194-2017. 
Es probable que este giro se haya debido a la presión de los litigantes, frustrados por la dificultad de acceder a la Corte Suprema. Es asimismo probable que esta presión se haya apoyado en la supuesta infracción de un supuesto derecho al recurso. Acerca de este punto se vuelve en la tercera sección.

\section{El EFECTO DE LA SENTENCIA DE UNIFICACIÓN}

Una jurisprudencia uniforme contribuye al estado de derecho mediante su proyección hacia el futuro: el modo en que el derecho ha sido aplicado constituye una señal acerca de cómo será aplicado. Así, la jurisprudencia pasa a integrar el universo de directivas a disposición de las personas que buscan ajustar su actuar al derecho.

Esta proyección a futuro suele estar detrás de propuestas que buscan atribuir formalmente a los precedentes carácter vinculante ${ }^{11}$. Estas son de lege ferenda cuando se propone su introducción formal, por medio de una ley ${ }^{12}$. Son de lege lata cuando se afirma que ciertas sentencias ya son, siquiera en algún sentido, vinculantes. Este es el caso de Díaz, quien precisamente ha sostenido que las sentencias de unificación de la Corte Suprema constituyen precedentes que deben ser seguidos ${ }^{13}$. En lo que sigue sostendré que esta tesis es incorrecta.

Díaz defiende una tesis débil, según esto, de no seguirse el precedente, la decisión "es legal, pero puede ser criticada en sus fundamentos y ser objeto de revocación mediante recurso" 14 . Esta tesis está asociada a lo que a veces se denomina vinculación de facto, utilizada para referirse a aquellos sistemas europeo continentales que, a pesar de

11 "[S]e debe introducir de manera decidida el seguimiento del precedente en el ordenamiento jurídico chileno... esta es la única manera de uniformar la jurisprudencia, pues mediante dicho seguimiento se evita la dispersión jurisprudencial”. Díaz García, 2015b, p. 414.

12 Así, por ejemplo, ibid.

${ }^{13}$ DíAz García, 2015a.

${ }^{14}$ Ibid., citando a PeCZenik, 1997, p. 463. Además de lo citado en el texto principal, Díaz también define su tesis así: "el precedente opera como una regla de decisión que debe ser seguida, de modo que se debe respetar a menos que existan buenas razones para apartarse de él” (ibid.). Al utilizar dos criterios distintos introduce ambigüedad en la definición de la tesis que defiende.

Peczenik clasifica las posibilidades de un sistema jurídico frente a los precedentes conforme a tres criterios. En primer lugar, atiende a las consecuencias que tiene no seguir un precedente. De aquí resulta que los precedentes pueden ser: formalmente vinculantes (cuando apartarse del precedente constituye un error que debe ser corregido), no formalmente vinculantes, pero con fuerza (cuando apartarse del precedente acarrea crítica y la posibilidad de revocación), no formalmente vinculantes y desprovistos de fuerza, pero dotados de valor justificativo (cuando apartarse del precedente solo significa que la decisión queda más débilmente justificada que si se lo hubiera seguido) y meramente ilustrativos. Luego, Peczenik clasifica las dos primeras categorías conforme a un segundo y tercer criterios: si se admite o no que un precedente sea generalmente revocado (segundo criterio) o no seguido en casos particulares (tercer criterio) bajo ciertas condiciones. Peczenik no utiliza la expresión prima facie, pero ella parece adecuada para referirse a los precedentes formalmente vinculantes o con fuerza, siempre que se admita que puedan ser revocados o no seguidos cuando se dan ciertas condiciones. Esto corresponde con un precedente que debe ser seguido, "a menos que 
no reconocer a la jurisprudencia carácter de fuente formal, atribuyen algún grado de fuerza normativa a los precedentes ${ }^{15}$.

Díaz ofrece dos argumentos para sostener la tesis del efecto vinculante débil. Los denominaré lógico y pseudorrealista. El argumento lógico parte de la premisa de que la finalidad del recurso es la unificación de jurisprudencia. Díaz afirma que "quien sostiene que la unificación de la jurisprudencia es el objetivo del recurso de unificación de jurisprudencia... de manera lógicamente necesaria está sosteniendo que se deben seguir los precedentes fijados al resolver este recurso" 16 . Para ser esto cierto, se requiere sin embargo otra premisa: que la obligación de seguir los precedentes sea la única manera en que un recurso puede contribuir a la uniformidad jurisprudencial. Esta premisa no se encuentra justificada.

Es perfectamente concebible un sistema con jurisprudencia uniforme sin obligación alguna de seguir los precedentes. Bastaría para ello que el tribunal supremo tuviera una integración estable, que sus integrantes mantuvieran criterio constante y que tuviera competencia en aquellos asuntos en que hay dispersión jurisprudencial. Aun sin precedentes vinculantes, la uniformidad estaría asegurada mediante la posibilidad de recurrir al supremo. Por eso se ha afirmado, correctamente, que el recurso de casación en el fondo también tiene la uniformidad jurisprudencial como uno de sus objetos principales ${ }^{17}$.

La integración de la Corte es, sin embargo, extremadamente inestable ${ }^{18}$. Se ha sostenido que también lo son las opiniones de sus ministros ${ }^{19}$. Resulta entonces plausible afirmar que cateris paribus, un recurso que le da competencia para conocer de la dispersión jurisprudencial no resulta idóneo para producir uniformidad. Pero un sistema que reconoce una estricta vinculación de los tribunales a los precedentes tampoco produciría uniformidad a menos que el tribunal supremo fuera constante en su jurisprudencia. En otras palabras, no es posible producir uniformidad jurisprudencial allí donde el propio tribunal supremo genera dispersión, con total independencia de la obligatoriedad de los precedentes. Aunque resulte paradójico, en ese caso dicha uniformidad puede lograrse mejor limitando la competencia de dicha Corte. Acerca de esto volveremos más adelante.

existan buenas razones para apartarse de él” (Díaz, cit.), pero esto no es lo mismo que un precedente que de no ser seguido da lugar a que la decisión sea criticada y posiblemente revocada.

La tesis de la vinculación o fuerza prima facie asume que los precedentes son vinculantes o tienen algún grado de fuerza normativa. Por eso Díaz debe necesariamente asumir que la sentencia de unificación es vinculante (tesis fuerte) o está al menos dotada de cierta fuerza normativa (tesis débil). Por otra parte, aunque se refiera a vinculación prima facie, en su texto Díaz ostensiblemente se refiere a la clasificación que hace Peczenik conforme al primer criterio. Por todo ello, asumiré que García defiende al menos la tesis débil.

15 Peczenik, 1997 y Peczenik, 2000.

16 Díaz García, 2015 a, p. 438 y n. 47.

${ }^{17}$ Ver, por todos, Calamandrei, 1961, pp. 91 ss (referido al derecho italiano, en lo pertinente análogo al chileno). Entre nosotros, véase Valenzuela Villalobos, 2015, p. 463 s.

18 Esta inestabilidad se debe a la modalidad de integración de las distintas salas. Según PARDOw Lorenzo y CARbonell Bellolio, 2018, solo la tercera sala de la Corte tuvo, entre 2009 y 2013, cincuenta integraciones diferentes.

${ }^{19}$ Vergara Blanco, 2019, estudio que aún espera una revisión crítica. 
El problema podría enfrentarse sometiendo a la Corte a la obligación de seguir sus propios precedentes ${ }^{20}$. Pero esto introduciría entre nosotros una institución inusual incluso en los sistemas que tradicionalmente han reconocido el carácter formalmente vinculante de los precedentes. Como sea, el hecho de que someter a la propia Corte a la obligación de seguir su jurisprudencia pudiera contribuir a la uniformidad jurisprudencial, no es suficiente para sostener que el legislador, al crear el recurso de unificación, impuso dicha obligación.

Díaz ofrece también un argumento que he denominado pseudorrealista. Afirma que la jurisprudencia de unificación ha tenido un efecto unificador, que atribuye a que la Corte ha seguido su propia jurisprudencia cuando ha conocido de una misma materia de derecho. Esto lo ha justificado adecuadamente ${ }^{21}$. De ello colige que se encuentra "racionalmente justificado, que el objetivo del recurso de unificación de jurisprudencia laboral ha sido introducir el seguimiento del precedente en el ámbito procesal laboral chileno”. Aquí hay un non sequitur. Si la Corte mantiene una jurisprudencia estable respecto de un asunto cualquiera, sea cual sea el recurso por el que haya conocido de él, sin duda unificará la jurisprudencia. Pero esto no significa que el objetivo del recurso haya sido introducir el seguimiento del precedente en el ámbito respectivo. Lo único que significa es que la Corte, por razones que merecen ser investigadas, ha mantenido una jurisprudencia razonablemente consistente ${ }^{22}$.

Para formular un genuino argumento realista sería necesario que la Corte mantuviera una jurisprudencia uniforme con independencia de las opiniones que sus integrantes tuvieran de su mérito. Solo entonces sería posible predecir que en el futuro los jueces seguirían los precedentes. Díaz no ha hecho tal ${ }^{23}$. Y lo cierto es que un estudio de la

${ }^{20} \mathrm{Al}$ presentar su tesis, Díaz nada dice sobre este punto. Sin embargo, durante el desarrollo de su trabajo, afirma que el comportamiento de la Corte Suprema "permite confirmar... que la finalidad del medio de impugnación en referencia es uniformar la jurisprudencia, lo que se logra mediante el seguimiento de su propio precedente”. Díaz García, 2015a, p. 436.

${ }^{21}$ Díaz García, et al., 2014.

${ }^{22}$ Esta uniformidad se ha debido a una relativa estabilidad en la integración de la Cuarta Sala, que conoce del recurso de unificación de jurisprudencia. Es por eso que cambios en su integración se han traducido en cambios en la jurisprudencia. Ya advertía el propio Díaz García, 2015b el giro jurisprudencial que se producía el 2014 y que coincidió con un cambio importante en la integración de la sala.

${ }^{23}$ En nota al pie, Díaz afirma que "que la Corte Suprema ha entendido y aplicado el recurso en cuestión bajo la lógica de seguimiento del precedente en el período referido”. Díaz García, 2015a, n. 45. En el mismo sentido, Díaz García, et al., 2014. Como evidencia, Díaz señala, primero, la uniformidad que de facto se produjo desde que se creó el recurso hasta abril de 2013 (fecha en que se dicta la última sentencia de la muestra analizada) y, segundo, la transcripción literal de la misma ratio decidendi en los fallos de unificación sobre una misma materia. Lo primero, como se dice en el texto principal, solo demuestra consistencia, la que puede deberse a múltiples factores no analizados, particularmente la estabilidad en la integración de la sala. Lo segundo más bien demuestra lo contrario de lo que se pretende. En un sistema que reconoce valor a los precedentes, el precedente no se transcribe, sino que se cita. La transcripción más bien demuestra que la Corte estima insuficiente la sola referencia al precedente para justificar su decisión, de manera que reitera la fundamentación. Esto es consistente con una larga tradición que desconoce el valor de los precedentes. Así, puede leerse en el decreto-lei de 1 de marzo de 1837, aclaratorio del de 2 de febrero del mismo año que introdujo la obligación de fundar las sentencias, que "En defecto de la lei [sic] escrita, debe juzgarse como ha 
jurisprudencia permite más bien constatar lo siguiente: (1) las Cortes de Apelaciones no se consideran vinculadas por las sentencias de unificación dictadas por la Corte Suprema ${ }^{24}$; (2) dichas Cortes no estiman que la cita de un "precedente" de la Corte Suprema sea por sí sola suficiente para fallar un recurso de nulidad ${ }^{25}$; (3) la Corte Suprema no considera que las Cortes de Apelaciones incurran en error por el solo hecho de desconocer la jurisprudencia unificada ${ }^{26}$, ni (4) ve en sus "precedentes" fuerza alguna que limite su libertad para cambiar su jurisprudencia ${ }^{27}$.

Al fracasar los dos principales argumentos que ofrece Díaz para justificar su tesis débil de vinculación, es difícil resistir la interpretación estándar del artículo 438-C del Código del Trabajo: "El fallo que se pronuncie sobre el recurso solo tendrá efecto respecto de la causa respectiva”. Esta interpretación sostiene que la disposición transcrita expresamente excluye todo efecto de precedente vinculante a las sentencias de unificación ${ }^{28}$.

Se debe sin embargo conceder a Díaz lo siguiente: resultaría anómalo que se hubiera creado un recurso con la precisa finalidad de unificar jurisprudencia y que su única contribución consistiera en otorgar competencia a un tribunal que no se ha caracterizado por su estabilidad doctrinaria. ¿En qué se diferenciaría de otros recursos que otorgan competencia a dicha Corte? ¿Podría la sentencia de unificación tener algún efecto unificador blando distinto de su fuerza como precedente para casos futuros?

sido costumbre juzgar en iguales casos; mas sin citar... las sentencias de otros Tribunales, sino los principios generales de derecho o razones que motivaron antes a aquellos tribunales a fallar del modo que lo hicieron...".

${ }^{24} \mathrm{Ni}$ siquiera se sienten obligadas a dar cuenta de la existencia de jurisprudencia de unificación. Vid., por ejemplo, Corte de Apelaciones de Valparaíso, 12.7.2017, rol 345-2017. Esta sentencia acogió un recurso de nulidad con fundamento en una doctrina contraria a la reiterada jurisprudencia de unificación de la Corte Suprema (1.4.15, rol 11584-2014, 6.8.2015, rol 23647-2014, 28.4.2016, rol 7091-2015, entre otras). Ella fue unánime y no contiene referencia alguna a la jurisprudencia de unificación.

${ }^{25}$ Cuando les sirven de apoyo, las Cortes ciertamente citan sentencias de nulidad de la Suprema. Pero esta cita es siempre un argumento adicional, no uno que por sí solo se estime suficiente para fundamentar el fallo. Por otra parte las citas suelen ser transcripción literal de considerandos, sin intentar extraer la ratio decidendi de la sentencia. Vid., por ejemplo, Corte de Apelaciones de Temuco, 25.5.2017, rol 270-2016, considerando cuarto.

${ }^{26}$ Vid., por ejemplo, Corte Suprema, 15.5.18, rol 36770-2017, donde acoge el recurso contra la sentencia de la Corte de Valparaíso citada en n. 17 supra, sin formular reproche alguno por haber esta ignorado la clara línea jurisprudencial de la primera. Esta sentencia es ilustrativa de la práctica ordinaria.

${ }^{27}$ En ocasiones, cuando un ministro conscientemente cambia el criterio hasta entonces sostenido, deja constancia de ello en la sentencia. En otras palabras, los ministros sienten un imperativo a la consistencia personal. La fuerza de los precedentes se vincula en cambio a la consistencia institucional. Si la Corte cambia su jurisprudencia, no se siente obligada a hacerse cargo argumentativamente de la fuerza que tendría el hecho de haber sostenido la línea jurisprudencial que abandona. Vid., por ejemplo, Corte Suprema, 20.11.2017, rol 8090-2017, que introdujo un giro importante en la jurisprudencia de la Corte. Esta sentencia es ilustrativa de la práctica ordinaria.

${ }^{28}$ Díaz sostiene que "solo" está referido a la regla que sigue: "y en ningún caso afectará a las situaciones jurídicas fijadas en las sentencias que le sirven de antecedente”. Ya desde el punto de vista exegético esta interpretación es discutible, pues transforma la primera cláusula en redundante. Resulta más conforme al principio de interpretación útil entender que el "solo" excluye efecto a futuro (precedente), mientras que la segunda cláusula excluye efecto retroactivo. Fuera de la cuestión exegética, la debilidad de la tesis de Díaz radica en la crítica desarrollada en el texto principal. 
Lo peculiar de la sentencia que resuelve el recurso de unificación de jurisprudencia se comprende cuando se advierte la indisoluble relación que existe entre la condición principal de admisibilidad del recurso y la sentencia que lo resuelve. Aquella consiste en la existencia de "distintas interpretaciones sostenidas en uno o más fallos firmes emanados de Tribunales Superiores de Justicia” respecto de una determinada materia de derecho. El efecto unificador blando consiste en eliminar dicha condición: desde que ella se dicta, ya no existen distintas interpretaciones acerca de la materia respectiva. ¿En qué sentido este efecto es algo más que aquel que cabe esperar de cualquier sentencia de la Corte Suprema y algo menos que un efecto vinculante?

Lo último es evidente. La circunstancia de que en un momento dado no exista ya dispersión jurisprudencial en torno a un punto no significa que los tribunales estén obligados a seguir la doctrina unificada. El recurso de unificación de jurisprudencia no garantiza que la dispersión no resurja en el futuro. En esto, el efecto estabilizador del recurso, al igual que ocurre con cualquier sentencia de la Corte Suprema, depende de la fuerza persuasiva de la sentencia de unificación.

Sin embargo, al eliminar la sentencia de unificación la dispersión jurisprudencial en torno a un punto de derecho se da un efecto procesal clarísimo, consistente en la imposibilidad de deducir un recurso de unificación fundado en la dispersión jurisprudencial eliminada ${ }^{29}$. De deducirse, el recurso debiera ser declarado inadmisible.

Es cierto que la declaración de inadmisibilidad del recurso de unificación de jurisprudencia requiere unanimidad. Por unanimidad también puede la Corte declarar la manifiesta falta de fundamento de un recurso de casación en el fondo. Pero hay una gran diferencia entre ambas instituciones. Quien concurre a rechazar por manifiesta falta de fundamento un recurso de casación correctamente formulado, solo puede hacerlo por estimar que la sentencia recurrida aplica correctamente el derecho. Esta es la pregunta que cada ministro debe hacerse: “¿Estimo que la sentencia recurrida ha aplicado correctamente el derecho y en consecuencia concurro con mi voto a rechazar el recurso por manifiesta falta de fundamento?”. Distinta es la pregunta que debe hacerse cada ministro en el examen de admisibilidad del recurso de unificación: “¿Hay dispersión jurisprudencial?”. Esta pregunta no involucra en modo alguno consideraciones en torno a si la jurisprudencia es o no acertada ni, en consecuencia, a la opinión personal que tenga cada ministro referente al fondo ${ }^{30}$. Es por eso posible responderla así: "La Corte unificó la dispersión existente. Discrepé de esa unificación, pero mi opinión no prevaleció y disentí. Si la jurisprudencia se vuelve a dispersar, insistiré en mi opinión e intentaré persuadir a la mayoría. Pero la sentencia aquí recurrida es consistente con la doctrina actualmente unificada. No habiendo por ahora dispersión jurisprudencial, no me queda más que concurrir con mi voto a declarar la inadmisibilidad del recurso".

29 Este efecto no es advertido por FÁBREgA VEGA, 2010, quien por eso concluye que podría "llevarse al absurdo de contemplar la posibilidad de 'unificar' criterios ya 'unificados'” (p. 531).

${ }^{30}$ Precisamente por esta razón, Delgado Castro, 2015, manifiesta una preferencia por el recurso de casación por sobre el de unificación. De la misma opinión parece ser HALPERN Montecino, 2013, p. 12. 
Este efecto tiene indudables virtudes. En primer lugar, modera la oscilación jurisprudencial que resulta de la inevitable discrepancia al interior de la propia Corte. No es posible esperar consistencia en la jurisprudencia aun si cada ministro mantuviera su opinión en el tiempo, pues los ministros llamados a resolver una misma materia suelen variar, sea por su inevitable retiro y reemplazo, sean titulares, suplentes o abogados integrantes, como por cambios en la integración de sus salas. Una parte de lo anterior resulta deseable en cualquier sistema jurídico. La jurisprudencia debe evolucionar y esta evolución se facilita con la renovación de la Corte que es consecuencia del (hasta ahora) inevitable envejecimiento y muerte de los seres humanos. Es por eso que el comité judicial de la Cámara de los Lores británica anunció en 1966 que dejaría de estar rigurosamente vinculada por sus propios precedentes ${ }^{31}$.

El problema no es entonces la evolución de la jurisprudencia, sino su oscilación. En el caso de la Corte Suprema, esta se debe principalmente a la inestabilidad en la integración de sus salas. La uniformidad es particularmente vulnerable cuando la jurisprudencia se sostiene por una mayoría de tres ministros, pues la ausencia puntual de cualquiera de ellos (que ocurre rutinariamente) puede significar un giro. Este giro, que no es consecuencia de un cambio estable en la composición de la Corte sino solo de un accidente en la integración de la sala, puede durar tanto como dure dicho accidente ${ }^{32}$.

La unificación reduce significativamente el riesgo de oscilación, porque permite a la Corte declarar inadmisibles los recursos de unificación fundados en una dispersión que ha sido eliminada por una sentencia unificadora, aun cuando esta haya sido acordada por una mayoría de tres ministros. Mientras una Corte de Apelaciones no vuelva a desafiar la doctrina unificada, la Corte Suprema no volverá a conocer de la materia, quedando así la unificación inmune a los recurrentes accidentes en la integración de sus salas.

Este efecto tiene la virtud adicional de contribuir a una utilización más racional del tiempo de la Corte. Una sala suele ver entre dos y cuatro causas de tabla por audiencia. El tiempo de la Corte es un valiosísimo (y carísimo) bien público. La admisibilidad debiera contribuir a que las causas que ocupan esos limitadísimos espacios de tiempo justifiquen la atención de la Corte. No se justifica dicha atención cuando el asunto

${ }^{31}$ Reino Unido, Lord Chancellor (Lord Gardiner), Practice Statement (1966), [1966] 3 All ER 77. La Cámara de los Lores había adoptado la práctica de sentirse vinculada por sus propios precedentes recién en 1861. Véanse Dworkin, 1962 y Blom-Cooper, 2011. Por regla general, los tribunales superiores de justicia no se encuentran vinculados por sus propios precedentes. Véase TARUFFo, 1997, p. 439.

32 Ejemplo de ello es lo ocurrido en la Cuarta Sala en relación con la pregunta de si está sujeta a contrato de trabajo la relación entre una persona contratada a honorarios por la Administración cuando no se cumplen los requisitos que establecen los artículos 11 de la Ley $\mathrm{N}^{\circ} 18.834$ o cuarto de la Ley $\mathrm{N}^{\circ} 18.883$ (administración municipal). A mediados de 2015 la Corte Suprema había unificado varias veces la jurisprudencia en sentido afirmativo. El día 30 de junio de 2015, integrada la sala con solo dos de sus ministros regulares (Blanco y Chevesich), vio una recurso sobre esta materia. En sentencia de unificación de 5 de agosto de 2015, la Corte unificó en sentido contrario a la jurisprudencia de la sala (ministro Aránguiz y abogados integrantes Correa y Prado), con el voto en contra de sus únicos ministros regulares (Corte Suprema, 5.8.2015, rol 249042014). Al día siguiente, la Corte retomó su línea jurisprudencial (Corte Suprema, 6.8.2015, rol 23647-2014, ministros Chevesich, Muñoz, Cerda y abogado integrante Lagos, con voto en contra del abogado integrante Prado). Cf. Vergara Blanco, 2016. 
viene fallado de un modo consistente con la unificación de la Corte y ninguna Corte de Apelaciones ha desafiado esta unificación.

\section{Sobre EL DERECHO AL RECURSO}

La tesis aquí defendida importa desconocer al litigante vencido un derecho subjetivo a que la Suprema revise la sentencia que lo agravia. Esto es consistente con la explícita declaración legal de que el recurso puede interponerse excepcionalmente en caso de dispersión jurisprudencial (Código del Trabajo, art. 483, inciso primero). El recurso de unificación responde al interés público en una jurisprudencia uniforme, no al interés del litigante vencido en que la sentencia que lo agravia sea revisada por la Corte, que pasa a ser un instrumento al servicio del primero $^{33}$.

¿Es inconstitucional esta subordinación del interés del litigante? ¿Garantiza la Constitución su derecho a que la sentencia que lo agravia sea revisada por la Suprema? Alguna doctrina y jurisprudencia han reconocido en la Constitución un "derecho al recurso" que podría justificar una respuesta afirmativa, y que quizás explique el giro de la Corte a mediados de 2017. Contra esta hipótesis, defenderé la tesis de que el litigante vencido en un juicio laboral no tiene derecho constitucional a recurrir a la Corte Suprema.

Desde luego, ninguna disposición constitucional reconoce explícitamente a los litigantes vencidos un derecho genérico a recurrir a la Corte Suprema. Tampoco a los litigantes vencidos en juicios laborales ${ }^{34}$. De existir, tal derecho debe encontrarse implícito en disposiciones constitucionales que no lo mencionan.

La Constitución dispone que "Corresponderá al legislador establecer siempre las garantías de un procedimiento” racional y justo (artículo $19 \mathrm{~N}^{\circ} 3$ inc. sexto). Esta disposición concede al legislador una competencia que también le confía el artículo 63 No 3 de la misma Constitución: "Solo son materias de ley... Las que son objeto de codificación... procesal...”. Pero la primera disposición enmarca esta atribución de competencia en un parámetro normativo que limita al legislador: racionalidad y justicia procesales. Queda al intérprete constitucional determinar aquel parámetro, respetando una amplia prerrogativa legislativa para optar por procedimientos de características muy diversas ${ }^{35}$. La cuestión que nos ocupa concierne a la determinación de dicho parámetro en un ámbito específico: ¿exigen la racionalidad y justicia procesales, reconocer al litigante vencido un derecho a que la sentencia que pronuncia una Corte de Apelaciones conociendo de un recurso de nulidad en juicio laboral sea revisada por la Corte Suprema?

${ }^{33}$ La primacía del interés público también ha caracterizado a la casación. Véase PAsTor, 2001, p. 27, citado por Valenzuela Villalobos, 2015, p. 464.

${ }^{34}$ Los únicos litigantes vencidos que tienen un derecho constitucional a recurrir a la Corte Suprema son el parlamentario, gobernador regional, delegado presidencial regional o delegado presidencial provincial desaforados por resolución de tribunal de alzada. Constitución Política, artículos 61, inciso segundo y 124 , inciso sexto.

${ }^{35}$ Véase sentencia del Tribunal Constitucional, 30.1.2008, rol 986, considerandos 18 y 22. 
El derecho al recurso tiene su origen en los artículos 8.2.h de la Convención Americana de Derechos Humanos y 14.5 del Pacto Internacional de Derechos Civiles y Políticos. Este derecho se limita, sin embargo, a los procesos penales y, en estos, su titular es exclusivamente el condenado ${ }^{36}$.

El Tribunal Constitucional chileno, sin embargo, ha extendido el derecho del recurso $^{37}$. A la fecha de redacción de este trabajo ha pronunciado 100 sentencias concernientes a la materia. De estos, solo 11 se refieren al derecho al recurso del condenado penal ${ }^{38}$. Igual número de casos examinan el derecho al recurso de otros intervinientes en procedimientos penales ${ }^{39}$. En 78 casos el Tribunal explora el derecho al recurso en ámbitos distintos del penal, pero en ninguno ha examinado la cuestión de que aquí se trata ${ }^{40}$. Es admisible sin embargo preguntarse hasta qué punto el Tribunal Constitucional ha desarrollado una doctrina que justifique reconocer que el litigante vencido en juicio laboral tiene un derecho constitucional a llegar a la Suprema. Una ojeada a su jurisprudencia desmiente tal posibilidad.

En estos 100 casos el Tribunal ha examinado la constitucionalidad de 34 instituciones que limitan un posible derecho al recurso ${ }^{41}$. De estas instituciones, 14 han sido objeto de dos o más pronunciamientos ${ }^{42}$. Si se las examina individualmente, se verá que solo

${ }^{36}$ Esto es explícito en el Pacto Internacional de Derechos Civiles y Políticos. Para la Convención Americana de Derechos Humanos, véase Ibáñez Rivas, 2014, p. 243 y Salas Salazar, 2014.

${ }^{37}$ Esta jurisprudencia tiene un antecedente remoto en sentencia de inaplicabilidad de la Corte Suprema que afirmó que el derecho a un racional y justo procedimiento comprende "la facultad de interponer recursos para revisar las sentencias dictadas por tribunales inferiores" (5.12.2001, rol 3643-2000). Este dictum fue citado con aprobación por el Tribunal Constitucional (8.8.2006, rol 478-2006, considerando 14).

38 30.1.2008, Rol 986; 7.10.2008, Rol 1130; 5.8.2010, Rol 1432; 26.8.2010, Rol 1443; 31.8.2011, Rol 1501; 18.7.2017, Rol 3103; 20.3.2018, Rol 3338; 22.3.2018, Rol 3150; 10.4.2019, Rol 4187; 13.8.2019, Rol 5878, y 3.10.2019, Rol 5750). En todas estas sentencias el Tribunal desestimó el reclamo de inconstitucionalidad. La calificación de una causa como acogida o rechazada se refiere exclusivamente a la decisión del Tribunal en relación con la alegación relativa al derecho al recurso.

39 De estas, cuatro impugnaciones fueron acogidas (28.1.2010, Rol 1535; 30.12.2014, Rol 2628; 11.7.2017, Rol 3197, y 18.11.2019, Rol 5666) y siete rechazadas (1.4.2008, Rol 821; 29.1.2013, Rol 2330; 9.1.2014, Rol 2354; 9.1.2014, Rol 2323; 30.10.2014, Rol 2615; 29.6.2017, Rol 3123, y 4.9.2018, Rol 3721).

${ }^{40}$ Los casos laborales de que ha conocido se refieren, el primero, a la improcedencia del recurso de apelación contra la sentencia de instancia pronunciada en un segundo juicio realizado como consecuencia de la anulación del primero (23.4.2019, Rol 3886) y, el segundo, a la improcedencia de recursos contra la sentencia interlocutoria que falla excepciones (3.12.2019, Rol 6847). El Tribunal rechazó ambos recursos.

41 Para estos efectos, “institución” se refiere a una o más disposiciones legales que, en relación con una clase de procedimientos, en algún sentido limita la capacidad del litigante para que un tribunal revise una resolución que le causa agravio. Una misma disposición o conjunto de disposiciones, en cuanto resultan aplicables a distintas clases de procedimientos, se las considera como una institución para cada uno de los procedimientos a que se aplica. Así ocurre por ejemplo con la limitación de causales de casación en el fondo que establece el inciso segundo del artículo 768 del Código de Procedimiento Civil. Ella resulta aplicable a procedimientos especiales muy variados, lo que justifica tratarla como una institución respecto de cada uno de tales procedimientos.

42 Además de los casos señalados en la nota 72 supra, cada una de las siguientes restricciones ha sido objeto de un único pronunciamiento: A) Improcedencia de apelación: 1) contra resoluciones del juez de garantía (29.6.2017, Rol 3123, rechazado); 2) contra sentencia que acoge recurso de queja y deja sin efecto 
la mitad ha recibido un tratamiento consistente, ya sea afirmando o negando su constitucionalidad $^{43}$. Las otras siete han sido intermitentemente declaradas constitucionales

resolución de tribunal de juicio oral en lo penal que rebajó pena conforme al artículo 18 del Código Penal (20.3.2018, Rol 3338, rechazado); 3) contra sentencia que rechaza tercería en cobranza laboral (10.12.2019, Rol 6411, acogido); 4) contra sentencia que declara recargo del artículo 169 del Código del Trabajo en juicio de cobranza laboral (10.12.2019, Rol 6962, acogido), y 5) contra sentencia que falla reclamación contra resolución de intendente de encontrarse el reclamante obligado a contratar servicios de vigilantes privados (7.7.2011; Rol 1838; acogido). B) Improcedencia de todo recurso: 1) contra sentencia absolutoria penal dictada en un segundo juicio a consecuencia de la anulación del primero (1.4.2008, Rol 821, rechazado); 2) contra resoluciones del tesorero comunal que conoce de la ejecución de obligaciones tributarias (5.12.2017, Rol 3297, rechazado); 3) contra resolución que falla excepciones contra la ejecución en juicio de libre competencia (22.10.2019, Rol 6019, rechazado); 4) contra sentencia que falla reclamación contra resolución de Superintendencia de Seguridad Social que impone sanción por infracción en el otorgamiento de licencias médicas (10.4.2012, Rol 2181, donde el Tribunal desestimó cualquier inconstitucionalidad), y 5) contra sentencia que falla reclamación contra resolución de Superintendencia de Bancos e Instituciones Financieras que impone sanción por infracción a normas sobre operaciones de crédito de dinero (6.12.2013, Rol 2559, donde el Tribunal desestimó cualquier inconstitucionalidad). C) Improcedencia de casación en la forma: 1) contra sentencia que decreta la liquidación forzosa (25.6.2019, Rol 4313, rechazado), y 2) contra sentencia de primera instancia en juicio tributario (10.12.2019, Rol 7234). D) Exclusión de causales de casación en la forma contra la sentencia definitiva de única o segunda instancia en los siguientes procedimientos: 1) ambiental antiguo (22.6.2010, Rol 1373, acogido); 2) indemnización de perjuicios de la ley general de urbanismo y construcción (28.11.2018, Rol 3883, acogido); 3) reclamación contra la Dirección General de Aguas (15.11.2016, Rol 3042, acogido); 4) reclamación contra el Sistema de Evaluación Ambiental (21.12.2016, Rol 3097, acogido). E) Abandono del recurso de nulidad penal por no comparecencia (3.10.2019, Rol 5750, rechazado). F) Improcedencia del recurso de queja contra la sentencia que desestima recurso de nulidad en materia penal (18.7.2017, Rol 3103, rechazado).

${ }^{43}$ En primer lugar, el Tribunal en dos ocasiones ha desestimado la inconstitucionalidad de las disposiciones que impiden apelar la sentencia que dicta un tribunal de juicio oral en lo penal y que limita las causales de nulidad para recurrir en su contra (5.8.2010, Rol 1432 y 26.8.2010, Rol 1443). La segunda excepción se refiere a la disposición que en general impide recurrir contra la sentencia condenatoria penal dictada en un segundo juicio a consecuencia de la anulación del primero. El Tribunal ha sostenido invariablemente la constitucionalidad de esta restricción, no obstante lo sospechosa que ella resulta a la luz de los artículos 8.2.h de la Convención Americana de Derechos Humanos y 14.5 del Pacto Internacional de Derechos Civiles y Políticos (30.1.2008, Rol 986; 7.10.2008, Rol 1130; 5.8.2010, Rol 1432; 26.8.2010, Rol 1443; 31.8.2011, Rol 1501; 22.3.2018, Rol 3150; 10.4.2019, Rol 4187; 13.8.2019, Rol 5878). La tercera excepción se refiere a los artículos $102 \mathrm{H}$ y $102 \mathrm{~K}$ de la Ley $\mathrm{N}^{\circ}$ 19.968, que disponen que las sentencias dictadas en procesos ante juzgados de familia por infracciones cometidas por adolescentes son inapelables. El Tribunal ha acogido los tres requerimientos de inaplicabilidad (deducidos por una misma jueza) contra dichas disposiciones (3.3.2016, Rol 2743; 20.4.2017, Rol 3119, y 13.6.2019, Rol 4572). La cuarta excepción se refiere al artículo 12 del Auto Acordado sobre Procedimiento Aplicable al Convenio de La Haya relativo a los Efectos Civiles de la Sustracción Internacional de Niños y Niñas. El Tribunal ha rechazado en dos ocasiones que la citada disposición sea inconstitucional por no permitir recurrir de casación en la forma en contra de la sentencia de primera instancia (7.8.2018, Rol 4189 y 8.10.2019, Rol 6776). La quinta excepción se refiere a la improcedencia de decretar órdenes de no innovar en juicios de arrendamiento de bienes raíces urbanos, cuya inconstitucionalidad ha sido rechazada en cuatro ocasiones (20.12.2011, Rol 1907; 25.4.2013, Rol 2325; 29.6.2017, Rol 3298, y 8.9.2018, Rol 3938). La sexta excepción se refiere a la improcedencia de recursos en procedimientos de cancelación y suspensión de la licencia de conductor por acumulación de anotaciones de infracciones, cuya constitucionalidad ha sido confirmada en cuatro oportunidades (29.3.2012, Rol 1804; 3.4.2012, Rol 1888; 7.8.2012, Rol 2018, y 7.8.2012, Rol 2108). La séptima y última excepción se refiere a la improcedencia de casación en el fondo en procedimientos de policía local, que el Tribunal en tres ocasiones ha estimado constitucional (11.7.2017, Rol 3099 y 11.7.2017, Rol 3100, y 3.12.2019, Rol 5557). 
o inconstitucionales ${ }^{44}$. Esta oscilación refleja el bajo consenso al interior del Tribunal, el que se confirma al constatar que solo nueve sentencias de derecho al recurso han sido unánimes (todas ellas rechazando tal derecho en las circunstancias de los respectivos (asos) $)^{45}$. En las otras 91, el número de ministros disidentes asciende en promedio al $39 \%$ del Tribunal ${ }^{46}$.

En 46 sentencias el tribunal ha reconocido un derecho constitucional al recurso. La mayoría (35) han declarado la inconstitucionalidad de la limitación de las causales de procedencia del recurso de casación en la forma en juicios regidos por leyes especiales ${ }^{47}$. Y si bien en diez ocasiones el Tribunal ha desestimado la inconstitucionalidad de la limitación, nueve de ellas fueron anteriores al segundo semestre de $2017^{48}$. Desde entonces, el Tribunal ha declarado dicha disposición inconstitucional en 24 instancias. Y la única sentencia que en este período desestimó dicha inconstitucionalidad se debió a empate de votos, de manera que no cuenta como una opinión a favor de su constitucionalidad. Por otra parte, desde el 1 de julio de 2017 un promedio de 5,9 ministros ha estimado que la disposición es inconstitucional y un promedio de 3,4 mantiene la opinión contraria. En resumen, puede afirmarse que desde mediados de 2017 se ha establecido una frágil línea jurisprudencial en el sentido de que la limitación de las causales que autorizan a deducir el recurso de casación en la forma en procedimientos especiales no es racional ni justa. ¿Hasta qué punto esta línea jurisprudencial pudiera extrapolarse al recurso de

${ }^{4}$ A) La impugnación de la exclusión de causales de casación en la forma: 1) ha sido acogida en dos (4.6.2015, Rol 2677 y 13.6.2019, Rol 5849) y rechazada en dos oportunidades (6.8.2013, Rol 2137 y 10.12.2019, Rol 7231) en relación con juicios de arrendamiento de predios urbanos; 2) ha sido acogida en una ocasión (15.3.2018, Rol 3116) y rechazada en dos (24.12.2015, Rol 2798 y 12.6.2018, Rol 3054) en relación con juicios por reclamación contra multas de la Superintendencia de Valores y Seguros; 3) ha sido acogida en diez (25.8.2011, Rol 1873; 29.12.2016, Rol 2988; 6.3.2019, Rol 4347; 17.7.2019, Rol 5946; 24.9.2019, Rol 6877; 24.9.2019, Rol 6843; 24.9.2019, Rol 6658; 8.10.2019, Rol 6848; 8.10.2019, Rol 6715, y 8.10.2019, Rol 6714) y rechazado en una ocasión (26.5.2016, Rol 2797) en relación con juicios por reclamación contra alcalde; 4) ha sido rechazada en una (6.10.2016, Rol 2904) y acogida en tres oportunidades (27.12.2016, Rol 3008; 11.6.2019, Rol 5257, y 17.7.2019, Rol 5937) en relación con juicios por reclamación del monto pagado por expropiación; 5) ha sido rechazada tres (5.7.2012, Rol 2034; 3.9.2015, Rol 2723, y 21.7.2016, Rol 2862) y acogida cuatro veces (2.1.2015, Rol 2529; 17.10.2017, Rol 3365; 30.10.2018, Rol 4397, y 17.7.2019, Rol 5963) en relación con juicios tributarios antiguos y, por último, 6) ha sido rechazada dos (20.6.2017, Rol 3175 y 20.6.2017, Rol 3220) y acogida once veces (21.7.2016, Rol 2873; 21.7.2016, Rol 2898; 20.10.2016, Rol 2971; 13.11.2018, Rol 4398; 28.11.2018, Rol 4989; 28.11.2018, Rol 4376; 22.1.2019, Rol 3867; 6.3.2019, Rol 4043; 6.3.2019, Rol 4859; 16.9.2019, Rol 6656, y 10.12.2019, Rol 7234) en relación con juicios tributarios reformados. B) La impugnación contra el solve et repete en juicios de cobranza previsional ha sido acogida en dos (30.12.2019, Rol 7060, y 2.1.2020, Rol 7061) y rechazada en cuatro ocasiones (9.8.2011, Rol 1876; 17.10.2013, Rol 2452; 24.12.2015, Rol 2853, y 1.12.2016, Rol 2938).

45 1.4.2008, Rol 821; 5.8.10, Rol 1432; 26.8.2010, Rol 1443; 31.8.2011, Rol 1501; 25.4.2013, Rol 2325; 6.8.2013, Rol 2137; 17.10.2013, Rol 2452; 29.6.2017, Rol 3298, y 8.9.2018, Rol 3938.

${ }^{46}$ En promedio, las mayorías están conformadas por 5,52 ministros y las disidencias, por 3,61 ministros.

47 Véanse supra notas 74 (letra D) y 76 (letra A).

48 Véase supra nota 76 (letra A) (la sentencia de 10.12.2019, Rol 7231 no debe considerarse, pues el recurso fue desestimado por consideraciones procesales únicamente). 
unificación de jurisprudencia? Para responder es necesario examinar la analogía que pudiera presentar este recurso con el de casación en la forma.

El recurso de unificación de jurisprudencia abre un tercer grado jurisdiccional. El segundo grado jurisdiccional corresponde al recurso de nulidad. A propósito del recurso de unificación se pregunta entonces si existe un derecho a revisar la sentencia (de segundo grado) pronunciada con ocasión de un procedimiento de control de la sentencia de instancia (primer grado). Para esta pregunta no resulta pertinente la jurisprudencia del derecho al recurso contra la sentencia pronunciada en primer grado, pues las razones que pueda haber para reconocer ese derecho no son por sí solas suficientes para justificar un derecho a recurrir contra sentencias de segundo grado.

La casación en la forma, por su parte, es un recurso que puede deducirse contra sentencias dictadas tanto en primer como en segundo grado, dando así lugar a un segundo o tercer grado, respectivamente. De las 35 sentencias pronunciadas en torno al derecho al recurso de casación en la forma, 18 corresponden a limitaciones a la posibilidad de recurrir contra fallos dictados en primer grado ${ }^{49}$. No existe por tanto analogía entre la situación que ellas examinan y el recurso de unificación. De esta manera se reducen a 17 las sentencias pertinentes ${ }^{50}$.

Estas 17 sentencias se fundan en dos argumentos principales, ninguno de ellos es aplicable al recurso de unificación de jurisprudencia. El primer argumento afirma no permitir deducir el recurso de casación en la forma cuando la sentencia ha omitido alguno de los requisitos que enumera el artículo 170 del Código de Procedimiento Civil -lo que resulta inconsistente con la obligación de motivar las sentencias- que el Tribunal estima implícita en diversas disposiciones constitucionales. No es necesario examinar aquí los méritos de este argumento. Basta destacar que no alcanza al recuso de unificación de jurisprudencia, cuya única causal de interposición (dispersión de la jurisprudencia) no está directamente vinculada con la obligación de fundar las sentencias.

En segundo lugar el Tribunal entiende que si bien el legislador tiene amplia discrecionalidad para diseñar los recursos contra las resoluciones judiciales, discrimina arbitrariamente al ofrecer más causales de casación en la forma para juicios regidos por

${ }^{49}$ Este universo se compone de las diez sentencias dictadas en relación con reclamos de ilegalidad municipal (supra nota 76, letra A.3), que las cortes de apelaciones conocen en única instancia (véase Corte Suprema, 3.7.13, Rol 4266); de las sentencias pronunciadas en relación con reclamos contra la Superintendencia de Valores y Seguros (15.3.2018, Rol 3116) y contra la Dirección General de Aguas (15.11.16, Rol 3042), como también de una de las sentencias en procedimiento contra el Fisco por el monto pagado por expropiación (17.7.2019, Rol 5937), pues en los tres casos se reclamaba el derecho a recurrir ante la Corte de Apelaciones respectiva contra la sentencia dictada en primera instancia; de una sentencia que examina las restricciones para recurrir de casación en el fondo contra la sentencia de primera instancia dictada por un tribunal tributario y aduanero (10.12.19, Rol 7234) y, por último, de cuatro sentencias relativas al procedimiento tributario antiguo (2.1.15, Rol 2529; 17.10.17, Rol 3365; 30.10.18, Rol 4397 y 17.7.19, Rol 5963, pues la anomalía de que el juez de primera instancia fuera un funcionario del servicio público demandado justifica considerar que la sentencia de Corte de Apelaciones constituía la genuina primera instancia judicial.

50 Sentencias 22.6.10, Rol 1373; 4.6.15, Rol 2677; 21.7.16, Roles 2873 y 2898; 20.10.16, Rol 2971; 21.12.16, Rol 3097; 27.12.16, Rol 3008; 13.11.18, Rol 4398; 28.11.18, Roles 3883, 4376 y 4989 ; 22.1.19, Rol 3867; 6.3.19, Roles 4043 y 4859; 11.6.19, Rol 5257; 13.6.19, Rol 5849, y 16.9.19, Rol 6656. 
el Código de Procedimiento Civil que para juicios regidos por leyes especiales. Tampoco es necesario examinar la corrección de este argumento. Su aplicación al recurso de unificación de jurisprudencia llevaría a preguntarse si su limitado ámbito de aplicación a juicios laborales constituye una discriminación arbitraria al excluir otros juicios. Pero en ningún caso llevaría a cuestionar la interpretación que se ha defendido en la sección anterior por la causal de su interpretación. En efecto, dicha interpretación no importa diferenciación alguna entre clases de juicios. Simplemente afirma que el recurso es inadmisible cuando la sentencia impugnada es conforme a la última doctrina unificada y no existe sentencia alguna en contrario que con posterioridad haya vuelto a dispersar la interpretación de la respectiva materia de derecho.

En síntesis, no existe ningún antecedente jurisprudencial o doctrinario que permita afirmar que el litigante vencido en juicio laboral tiene derecho a que la Corte Suprema revise lo resuelto por Cortes de Apelaciones conociendo del recurso de nulidad. No hay entonces inconstitucionalidad alguna en la tesis que aquí se defiende, según esto solo es admisible el recuso de unificación de jurisprudencia cuando se satisfacen dos requisitos: que la sentencia que se impugna sostenga sobre la materia de derecho una interpretación a) distinta que la de al menos una sentencia de tribunales superiores (sentencia de contraste) que b) no corresponda a la doctrina unificada por la Corte Suprema con posterioridad a la sentencia de contraste.

\section{A MODO DE CONCLUSIÓN: REPARACIÓN POR VÍA LEGISLATIVA}

El estado de derecho exige que toda la actividad estatal se despliegue conforme a la ley. Eso supone que la ley sea clara, en el sentido de que sea posible emitir ex ante un juicio por las consecuencias jurídicas de una determinada acción u omisión. Esa claridad no puede descansar exclusivamente en la letra de la ley, sino que depende de la existencia de una jurisprudencia uniforme. Hay interés público tanto en que los asuntos sean resueltos conforme a derecho como en la uniformidad jurisprudencial. En el diseño procesal, estos intereses son funcionalmente separados: por regla general, el control de la resolución conforme a derecho se confía a las cortes de apelaciones, mientras que la función unificadora se confía a la Suprema. Hay para ello buenas razones. El control de la resolución de los asuntos conforme a derecho debe encontrarse generalmente disponible. El volumen de casos que ese control genera no puede ser absorbido por un único tribunal. Por tal razón debe ser confiado a las Cortes de Apelaciones ${ }^{51}$.

${ }^{51} \mathrm{La}$ Corte Suprema tiene una amplia competencia para conocer de apelaciones, que incluye los recursos de amparo y protección y diversas reclamaciones administrativas. Este diseño es irracional. Buena parte de estas apelaciones se conocen en cuenta, pues su volumen impide oír alegatos. Los amparos constituyen la excepción. Ello es posible porque los casos son muy semejantes y los abogados que comparecen son casi siempre los mismos, conocen muy bien a la Sala (Segunda) y rara vez necesitan más de cinco minutos para alegar. 
La función de unificación, por el contrario, debe ser absuelta por un único tribunal, de manera que ella no puede sino confiarse a la Corte Suprema. Eso exige limitar su competencia a los casos en que existe dispersión. Actualmente la Corte ejerce competencia más allá de lo que la correcta comprensión del recurso autoriza. La corrección de esta práctica podría lograrse mediante una ley como la siguiente:

Art. 1. Interprétase el inciso segundo del artículo 483 en el sentido de que no existen distintas interpretaciones sobre la materia de derecho objeto del juicio cuando la Corte Suprema ha unificado la jurisprudencia y, con posterioridad a la unificación, no se ha dictado sentencia alguna por cortes de apelaciones que sostengan una interpretación contraria a la misma.

Art. 2. Sustitúyese el inciso final del artículo 483-A por el siguiente: "Declarado admisible el recurso por el tribunal ad quem, el recurrido podrá deducir reposición dentro de quinto día, la que solo podrá fundar en la circunstancia de encontrarse la sentencia recurrida conforme con la jurisprudencia unificada o en que los fallos a que se refiere el inciso segundo no corresponden a sentencias ejecutoriadas”.

Art. 3. Agrégase el siguiente inciso final al artículo 483: "Procederá también el recurso cuando, no obstante encontrarse unificada la jurisprudencia por sentencia de la Corte Suprema, la resolución recurrida fuere anterior a la sentencia de unificación y sostuviere una interpretación incompatible con ella. En este caso, el recurso se conocerá y fallará en cuenta, para el solo efecto de anular la sentencia recurrida y dictar la correspondiente sentencia de reemplazo consistente con la jurisprudencia unificada, salvo que una mayoría de los ministros vote por traer los autos en relación para reconsiderar la jurisprudencia”.

\section{BIBLIOGRAFÍA}

Blom-Cooper, Louis, 2011: 1966 and All That: The Story of the Practice Statement, Oxford: Oxford University Press, pp. 128-144.

Calamandrei, Piero, 1961: La Casación Civil, tomo II (Bosquejo General del Instituto), Buenos Aires: Editorial Bibliográfica Argentina.

Delgado Castro, Jordi, 2011: "Examen Crítico del Recurso de Unificación de Jurisprudencia”, Revista de Derecho de la Pontificia Universidad Católica de Valparaíso, volumen XXXVI.

Delgado Castro, Jordi, Aspectos Problemáticos en Torno al Recurso de Unificación de Jurisprudencia Laboral, Santiago: Ediciones Jurídicas de Santiago.

DíAz GARcía, Luis Iván, 2015a: "Objetivo del Recurso de Unificación de Jurisprudencia Laboral”, Ius et Praxis, volumen 21, No 1 .

Díaz García, Luis Iván, 2015b: "Diez Razones para Incorporar el Seguimietno del Precedente en Chile”, Revista de Derecho Universidad Católica del Norte, volumen 22, № 2.

Díaz García, Luis Iván, Alarcón García, Sofía, Cempe Cempe, Katerine, Garrido Esparza, Luis Alejandro y ZÚÑIga Garrido, Alejandro, 2014: "Seguimiento del Precedente por la Corte Suprema de Chile en Materia Laboral. Estudio Empírico del Recurso de Unificación de Jurisprudencia", Revista Chilena de Derecho, volumen 41, $\mathrm{N}^{\circ} 3$. 
Dworkin, Gerald, 1962: "Stare Decisis in the House of Lords", The Modern Law Review, volumen $25, \mathrm{~N}^{\circ} 2$.

FÁBrega Vega, Hugo, 2010: “Asignaciones de Colación y Movilización: Unificación Jurisprudencial en Materia Laboral”, Actualidad Jurídica, volumen $\mathrm{N}^{\circ} 22$.

Halim MuÑoz, Fernando Andrés, 2010: El Recurso de Unificación de Jurisprudencia Laboral, Santiago: Thomson Reuters Puntolex.

Halpern Montecino, Cecily, 2013: El Recurso de Unificación de Jurisprudencia: ¿Un Recurso Excepcional?, Santiago: Colegio de Abogados de Chile A.G.

Halpern Montecino, Cecily y Humeres Noguer, Héctor, 2010: "La Intervención de la Corte Suprema en la Nueva Justicia del Trabajo: El Recurso de Unificación de Jurisprudencia”, Actualidad Jurídica, volumen XI, No 21.

Humeres Noguer, Héctor y Halpern Montecino, Cecily, 2015: La Unificación de la Jurisprudencia Laboral: Contexto Teórico, Análisis Doctrinal y Temático, Santiago: Legal Publishing Chile.

IbáÑez Rivas, Juana María, 2014: “Artículo 8. Garantías Judiciales”, en Christian Steiner y Patricia Uribe editores), Convención Americana sobre Derechos Humanos Comentada, México: Suprema Corte de Justicia de la Nación y Fundación Konrad Adenauer, pp. 207-254).

Pardow Lorenzo, Diego y Carbonell Bellolio, Flavia Emilia, 2018: "Buscando al 'Juez Mediano': Estudio sobre la Formación de Coaliciones en la Tercera Sala de la Corte Suprema”, Revista de Ciencia Politica, volumen 38, $\mathrm{N}^{\circ} 3$.

Pastor, Daniel R., 2001: La Nueva Imagen de la Casación Penal, Buenos Aires: Ed. Ad-Hoc.

Peczenik, Aleksander, 1997: The Binding Force of Precedent, en Neil MacCormick y Robert S. Summers (editores), Interpreting Precedents: A Comparative Study Aldershot: Darmouth Ashgate, pp. 461-479.

Peczenik, Aleksander, 2000: Acerca de los Precedentes Vinculantes de Facto, México: Fontamara.

Román Díaz, Fernando, 2008: "El Nuevo Recurso de Unificación de Jurisprudencia en la Reforma al Proceso Laboral (Un Extraño Recurso de Nulidad con Nombre de Fantasía)", Actualidad Jurídica, volumen $\mathrm{N}^{\circ} 18$.

Salas Salazar, Carolina, 2014: "Letelier Loyola, Enrique (2013). El Derecho Fundamental al Recurso en el Proceso Penal. Barcelona, Atelier Libros Jurídicos, 242 páginas”, Revista de Derecho Universidad Católica del Norte, volumen 21, $\mathrm{N}^{\circ} 1$.

Saldías Cárcamo, Camila Odette, 2013: "Recurso de Unificación de Jurisprudencia desde el Análisis Comparado", Actualidad Jurídica, volumen XIV, N 27.

Summers, Robert S., 1997: Departures from Precedent, en Neil MacCormick y Robert S. Summers (editores), Interpreting Precedents: A Comparative Study Aldershot: Darmouth Ashgate, pp. 519-530.

TARUFFo, Michele, 1997: Institutional Factors Influencing Precedents, en Neil MacCormick y Robert S. Summers (editores), Interpreting Precedents: A Comparative Study Aldershot: Darmouth Ashgate, pp. $437=460$.

Valenzuela Villalobos, Williams Eduardo, 2015: “¿Derecho a la Casación? Lectura a Contracorriente de la Jurisprudencia del Tribunal Constitucional”, Estudios Constitucionales, volumen $13, \mathrm{~N}^{\circ} 2$.

Vergara Blanco, Alejandro (2 de mayo de 2016), Contratos a honorarios para servicios personales habituales y dependientes en la Administración pública: su naturaleza laboral. El Código del Trabajo como estatuto común y supletorio. Recuperado el 9.9.2019: http://www.elmercurio. com/Legal/Noticias/Analisis-Juridico/2016/05/02/Contratos-a-honorarios-para-serviciospersonales-habituales-y-dependientes-en-la-Administracion-publica-su-naturaleza-laboral.aspx 
Vergara Blanco, Alejandro, 2019: "El Derecho Administrativo ante la Jurisprudencia de la Corte Suprema: Líneas y Vacilaciones. Veinte Temas, Diez Años (2008-2018)”, Revista de Derecho Administrativo Económico, volumen $\mathrm{N}^{\circ} 28$.

\section{Normas Jurídicas citadas}

Código de Procedimiento Civil, publicado con fecha 30 de agosto de 1902.

Código Tributario, publicado con fecha 31 de diciembre de 1974.

LEY N $\mathrm{N}^{\circ} 18.834$, estatuto administrativo, publicada con fecha 23 de septiembre de 1989.

LEY $\mathrm{N}^{\circ} 18.883$, estatuto administrativo para funcionarios municipales, publicada con fecha 29 de diciembre de 1989.

Convención Americana sobre Derechos Humanos, adoptada con fecha 22 de noviembre de 1969. Publicada en Chile con fecha 5 de enero de 1991.

Código Procesal Penal, publicado con fecha 12 de octubre de 2000.

Código del Trabajo, publicado con fecha 16 de enero de 2003.

LEY $\mathrm{N}^{\circ} 19.933$, otorga un mejoramiento especial a los profesionales de la educación que indica, publicada con fecha 12 de febrero de 2004.

\section{Jurisprudencia citada}

Corte de Apelaciones de Temuco, 25.5.2017, rol 270-2016

Corte de Apelaciones de Valparaíso, 12.7.2017, rol 345-2017.

Corte Suprema, 5.12.2001, rol 3643-2000.

Corte Suprema, 1.4.15, rol 11584-2014.

Corte Suprema, 5.8.2015, rol 24904-2014.

Corte Suprema, 6.8.2015, rol 23647-2014.

Corte Suprema, 25.8.2015, rol 29727-2014.

Corte Suprema, 25.8.2015, rol 30196-2014.

Corte Suprema, 25.8.2015, rol 30197-2014.

Corte Suprema, 29.12.2015, rol 3270-2015.

Corte Suprema, 29.12.2015, rol 4924-2015.

Corte Suprema, 29.12.2015, rol 5024-2015.

Corte Suprema, 29.12.2015, rol 5511-2015.

CORTE Suprema, 28.4.2016, rol 7091-2015.

Corte Suprema, 21.6.2017, rol 27910-2017

Corte Suprema, 25.7.2017, rol 31969-2017.

Corte Suprema, 3.8.2017, rol 14633-2017.

Corte Suprema, 8.8.2017, rol 34524-2017.

Corte Suprema, 16.8.2017, rol 34234-2017.

Corte Suprema, 16.8.2017, rol 34681-2014.

Corte Suprema, 21.8.2017, rol 35195-2017.

Corte Suprema, 29.8.2017, rol 30194-2017.

Corte Suprema, 16.11.2017, rol 2858-2017.

Corte Suprema, 20.11.2017, rol 8090-2017.

Corte Suprema, 14.12.2017, rol 10422-2017.

Corte Suprema, 22.5.2018, rol 37867-2017.

Corte Suprema, 16.8.2018, rol 42009-2017. 
Tribunal Constitucional, 5.12.2006, rol 478.

Tribunal Constitucional, 30.1.08, rol 986.

Tribunal Constitucional, 1.4.08, rol 821.

Tribunal Constitucional, 7.10.08, rol 1130.

Tribunal Constitucional, 28.1.10, rol 1535.

Tribunal Constitucional, 22.6.10, rol 1373.

Tribunal Constitucional, 5.8.10, rol 1432.

Tribunal Constitucional, 26.8.10, rol 1443.

Tribunal Constitucional, 7.7.11, rol 1838.

Tribunal Constitucional, 9.8.11, rol 1876.

Tribunal Constitucional, 25.8.11, rol 1873.

Tribunal Constitucional, 31.8.11, rol 1501.

Tribunal Constitucional, 20.12.11, rol 1907.

Tribunal Constitucional, 29.3.12, rol 1804.

Tribunal Constitucional, 3.4.12, rol 1888.

Tribunal Constitucional, 10.4.12, rol 2181.

Tribunal Constitucional, 5.7.12, rol 2034.

Tribunal Constitucional, 7.8.12, rol 2018.

Tribunal Constitucional, 7.8.12, rol 2108.

Tribunal Constitucional, 29.1.13, rol 2330.

Tribunal Constitucional, 25.4.13, rol 2325.

Tribunal Constitucional, 6.8.13, rol 2137.

Tribunal Constitucional, 17.10.13, rol 2452.

Tribunal Constitucional, 6.12.13, rol 2559.

Tribunal Constitucional, 9.1.14, rol 2323.

Tribunal Constitucional, 9.1.14, rol 2354.

Tribunal Constitucional, 30.10.14, rol 2615.

Tribunal Constitucional, 30.12.14, rol 2628.

Tribunal Constitucional, 2.1.15, rol 2529.

Tribunal Constitucional, 4.6.15, rol 2677.

Tribunal Constitucional, 3.9.15, rol 2723.

Tribunal Constitucional, 24.12.15, rol 2798.

Tribunal Constitucional, 24.12.15, rol 2853.

Tribunal Constitucional, 3.3.16, rol 2743.

Tribunal Constitucional, 26.5.16, rol 2797.

Tribunal Constitucional, 21.7.16, rol 2862.

Tribunal Constitucional, 21.7.16, rol 2873.

Tribunal Constitucional, 21.7.16, rol 2898.

Tribunal Constitucional, 6.10.16, rol 2904.

Tribunal Constitucional, 20.10.16, rol 2971.

Tribunal Constitucional, 15.11.16, rol 3042.

Tribunal Constitucional, 1.12.16, rol 2938.

Tribunal Constitucional, 21.12.16, rol 3097.

Tribunal Constitucional, 27.12.16, rol 3008.

Tribunal Constitucional, 29.12.16, rol 2988.

Tribunal Constitucional, 20.4.17, rol 3119.

Tribunal Constitucional, 20.6.17, rol 3175.

Tribunal Constitucional, 20.6.17, rol 3220. 
Tribunal Constitucional, 29.6.17, rol 3123. Tribunal Constitucional, 29.6.17, rol 3298. Tribunal Constitucional, 11.7.17, rol 3099. Tribunal Constitucional, 11.7.17, rol 3100. Tribunal Constitucional, 11.7.17, rol 3197. Tribunal Constitucional, 18.7.17, rol 3103. Tribunal Constitucional, 17.10.17, rol 3365. Tribunal Constitucional, 5.12.17, rol 3297. Tribunal Constitucional, 15.3.18, rol 3116. Tribunal Constitucional, 20.3.18, rol 3338. Tribunal Constitucional, 22.3.18, rol 3150. Tribunal Constitucional, 12.6.18, rol 3054. Tribunal Constitucional, 7.8.18, rol 4189. Tribunal Constitucional, 4.9.18, rol 3721. Tribunal Constitucional, 8.9.18, rol 3938. Tribunal Constitucional, 30.10.18, rol 4397. Tribunal Constitucional, 13.11.18, rol 4398. Tribunal Constitucional, 28.11.18, rol 3883. Tribunal Constitucional, 28.11.18, rol 4376. Tribunal Constitucional, 28.11.18, rol 4989. Tribunal Constitucional, 22.1.19, rol 3867. Tribunal Constitucional, 6.3.19, rol 4043. Tribunal Constitucional, 6.3.19, rol 4347. Tribunal Constitucional, 6.3.19, rol 4859. Tribunal Constitucional, 10.4.19, rol 4187. Tribunal Constitucional, 23.4.19, rol 3886. Tribunal Constitucional, 11.6.19, rol 5257. Tribunal Constitucional, 13.6.19, rol 4572. Tribunal Constitucional, 13.6.19, rol 5849. Tribunal Constitucional, 25.6.19, rol 4313. Tribunal Constitucional, 17.7.19, rol 5937. Tribunal Constitucional, 17.7.19, rol 5946. Tribunal Constitucional, 17.7.19, rol 5963. Tribunal Constitucional, 13.8.19, rol 5878. Tribunal Constitucional, 16.9.19, rol 6656. Tribunal Constitucional, 24.9.19, rol 6658. Tribunal Constitucional, 24.9.19, rol 6843. Tribunal Constitucional, 24.9.19, rol 6877. Tribunal Constitucional, 3.10.19, rol 5750. Tribunal Constitucional, 8.10.19, rol 6714. Tribunal Constitucional, 8.10.19, rol 6715. Tribunal Constitucional, 8.10.19, rol 6776. Tribunal Constitucional, 8.10.19, rol 6848. Tribunal Constitucional, 22.10.19, rol 6019. Tribunal Constitucional, 18.11.19, rol 5666. Tribunal Constitucional, 3.12.19, rol 5557. Tribunal Constitucional, 3.12.19, rol 6847. Tribunal Constitucional, 10.12.19, rol 6411. 
Tribunal Constitucional, 10.12.19, rol 6962.

Tribunal Constitucional, 10.12.19, rol 7231.

Tribunal Constitucional, 10.12.19, rol 7234.

Tribunal Constitucional, 30.12.19, rol 7060.

Tribunal Constitucional, 2.1.20, rol 7061.

Otras fuentes

ReINo Unido, Lord Chancellor (Lord Gardiner, Practice Statement (1966, [1966] 3 All ER 77. 